BMJ Open Sport \& Exercise Medicine

\title{
Sex and gender considerations in low back pain clinical practice guidelines: a scoping review
}

Tori Rathbone (1) , Catherine Truong, Haley Haldenby, Sara Riazi, Mara Kendall, Tayler Cimek, Luciana G Macedo (1)

\section{ABSTRACT}

Haldenby $\mathrm{H}$, et al. Sex and gender considerations in low back pain clinical practice guidelines: a scoping review. BMJ Open Sport \& Exercise Medicine 2020;6:e000972. doi:10.1136/ bmjsem-2020-000972

- Additional material is published online only. To view please visit the journal online (http://dx.doi.org/10.1136/ bmjsem-2020-000972).

Accepted 17 December 2020 used properly.
Check for updates

\section{(C) Author(s) (or their} employer(s)) 2020. Re-use permitted under CC BY-NC. No commercial re-use. See rights and permissions. Published by BMJ.

School of Rehabilitation Science McMaster University, Hamilton, Ontario, Canada

Correspondence to Dr Luciana G Macedo; macedol@mcmaster.ca
Objective The purpose of this scoping review is to determine if and how sex and gender have been incorporated into low back pain (LBP) clinical practice guidelines (CPG), and if sex and gender terms have been

Methods CPGs were searched on MEDLINE, Embase, NICE, TRIP and PEDro from 2010 to 2020. The inclusion criteria were English language, CGPs within physiotherapy scope of practice and for adult population with LBP of any type or duration. Three pairs of independent reviewers screened titles, abstracts and full texts. Guidelines were searched for sex/gender-related terms and recommendations were extracted. The AGREE II (Appraisal of Guidelines for Research and Evaluation II) was used to evaluate the quality of the CPGs.

Results Thirty-six CPGs were included, of which 15 were test-positive for sex or gender terms. Only $33 \%$ $(n=5)$ of CPGs incorporated sex or gender into diagnostic or management recommendations. Sixty percent of guidelines $(n=9)$ only referenced sex or gender in relation to epidemiology, risk factors or prognostic data, and made no specific recommendations. Overall, there was no observable relationship between guideline quality and likeliness of integrating sex or gender terms. The majority of guidelines used sex and gender terms interchangeably, and no guidelines defined sex or gender.

Conclusion CPGs did not consistently consider sex and gender differences in assessment, diagnosis or treatment of LBP. When it was considered, sex and gender terms were used interchangeably, and considerations were primarily regarding pregnancy. Researchers should consider the importance of including sex-based and/or gender-based recommendations into future LBP CPGs.

\section{INTRODUCTION}

Low back pain (LBP) is defined as pain located in the area between the posterior lower margins of the $12^{\text {th }}$ ribs and the gluteal folds, and may occur with associated lower limb pain/neurological involvement. ${ }^{12}$ LBP can be classified as acute (less than 6 weeks), subacute (6 to 12 weeks) or chronic (greater than 12 weeks). ${ }^{2}$ The origin of LBP is multifactorial, and is divided into non-specific LBP (NSLBP), specific, and serious pathologies. ${ }^{3}$

\section{What is already known?}

- Back pain is one of the most common conditions seen by family doctors and physiotherapists.

- Low back pain is highly prevalent with up to $80 \%$ of people experiencing at least one back pain episode in their lifetime.

- There are known sex and gender differences in the epidemiology, diagnosis and treatment of low back pain.

\section{What are the new findings?}

- Clinical practice guidelines (CPGs) do not consistently consider sex and gender differences in the assessment, diagnosis or treatment of low back pain.

- When sex or gender terms are considered, the terms are used interchangeably without regard to their strict definitions.

- When CPGs did consider sex or gender, the considerations primarily related to pregnancy, which is a subterm of sex, as it does not refer to sex but rather a transient period that is specific to one sex.

According to the 2017 Global Burden of Diseases, Injuries and Risk Factors Study, LBP was ranked number one for years lived with disability in 1990, 2007 and 2017, with increasing rates of occurrence for all ages. ${ }^{4}$

LBP research indicates significant differences between genders regarding prevalence, degree of disability and number of comorbidities; which are all higher in individuals who identify as women. ${ }^{5}$ Despite known differences, research studies that focus on LBP inconsistently report or fail to integrate sex or gender differences into their design, analysis and conclusions, ${ }^{6}$ and it is common to observe sex and gender terms used interchangeably. This practice can not only lead to misinterpretation of results, but also impact how evidence is applied.

In 2009, the Government of Canada made changes to the Health Portfolio in order to acknowledge the differing needs of men and 
women in relation to health, and defined sex and gender as independent descriptors. ${ }^{7}$ Sex was defined as a set of biological attributes in humans and animals that is most often associated with physical and physiological features of an individual (ie, reproductive/sexual anatomy). ${ }^{7}$ Sex was categorised as female or male, accounting that there are many variations in the biological attributes that are sex, and how the attributes may be expressed. ${ }^{7}$ Gender was referred to as the socially constructed role, behaviour, expression or identity of an individual (ie, girls, boys, women, men, gender diverse) and influences how people perceive themselves and others. ${ }^{7}$ Gender is often seen as binary (girl/woman and boy/man) but there is great diversity in how individuals experience and express gender. ${ }^{7}$ The 2016 Sex and Gender Equity in Research (SAGER) guidelines were designed for both authors and peer reviewers, with the intention of standardising sex and gender reporting in research. ${ }^{8}$ In 2017 Tannenbaum et $a l^{6}$ examined how sex and gender were integrated into Canadian clinical practice guidelines (CPGs) for non-communicable disease. Tannenbaum $e t$ $a t^{6}$ found that only $35 \%$ of guidelines made sex or gender specific recommendations, and only $25 \%$ of the studies used sex and gender terms correctly. ${ }^{6}$ Currently there are no reviews that specifically examine sex and gender considerations in LBP CPGs.

\section{Objectives}

The primary objective of this scoping review was to systematically examine if and how sex and gender was incorporated into LBP CPGs for adult populations, as it related to diagnosis, epidemiology, prognosis, risk factors and interventions. The secondary objective was to determine how sex and gender concepts have been used. The final objective was to determine if sex and gender representation was considered in the development of the guideline committee. A scoping review approach, which aims to provide a broad overview of a topic in order to identify key concepts and gaps in the literature, was deemed most appropriate due to the lack of known research on the topic of sex and gender in relation to LBP. $^{9}$

\section{METHODS}

The methodological framework for conducting scoping reviews, that was established by Arksey and O'Malley, ${ }^{10}$ and enhanced by Levac and colleagues, ${ }^{11}$ was used. The first five steps were followed, however, the sixth and final step, consulting with key stakeholders, was not performed, as a result of time constraints. ${ }^{11}$ This scoping review also followed the Preferred Reporting Items for Systematic Reviews and Meta-Analyses (PRISMA) extension for reporting guidelines for scoping reviews. ${ }^{12}$ The protocol for this scoping review was registered with OSF prior to title and abstract screening, in order to maintain transparency and reduce bias ${ }^{13}$ (10.17605/OSF. $\mathrm{IO} / 7 \mathrm{~S} 9 \mathrm{BD})$.

\section{Inclusion criteria}

All CPGs issued by a multinational committee, within the scope of physiotherapy (PT), with an adult population (18 years or older) focusing on primary LBP, were eligible for inclusion. LBP conditions that primarily related to cancer, fracture, infection, inflammatory diseases or other serious pathologies were excluded. All durations of LBP were eligible for inclusion. The methods were based off of the protocol by Oliveira et $a l,{ }^{14}$ but due to the high volume of guidelines, and recognising that sex and gender were unlikely to be considered prior to 2009, the inclusion criteria was adjusted after registration. ${ }^{13}$ After full-text screen, a limit of the past 10 years was applied and only the most recent version of a CPG was included, unless different topics were addressed. Only guidelines that were published in English were eligible.

\section{Outcomes}

The primary outcome was how sex and gender had been incorporated into healthcare recommendations within CPGs. Recommendations pertaining to diagnosis, epidemiology, prognosis, risk factors and interventions were considered. The secondary outcome addressed whether or not sex and gender concepts had been used as per the definitions that were previously outlined by the Government of Canada. ${ }^{7}$ Additionally, we examined whether diversity of sex and gender were considered in the development of the guideline research committee.

\section{Search strategy}

A search for CPGs was conducted on MEDLINE via Ovid (1946 to March 8 2020), Embase (1974 to March 9 2020), National Institute for Health and Clinical Excellence (NICE) (1999 to March 9 2020), Turning Research into Practice Medical Database (TRIP) (1997 to March 17 2020) and Physiotherapy Evidence Database (PEDro) (1999 to March 9 2020). There were no date limits applied. The following key terms were used in the search: low back pain and clinical practice guideline. A McMaster University (Ontario, Canada) Health Sciences Librarian was consulted to refine the search strategy. A comprehensive outline of the search strategy and the specific terms that were used can be found in online supplemental appendix A. This study excluded grey literature due to resource constraints. A manual search for CPGs included in the reference lists of the included studies was performed.

All eligible studies were imported to Covidence ${ }^{15}$ for removal of duplicates and screening. A pilot screen was completed by all reviewers for the first 10 titles/abstracts and full texts to ensure consistency. Three pairs of investigators (TR and HH, TC and MK and SR and CT) independently screened titles/abstracts and full texts. Any disagreements were discussed between the pair of reviewers, and if a consensus was not reached, a thirdparty investigator (LM) was consulted. 
Data extraction and analysis

The same calibration process, using the first three studies, was performed for data extraction procedures. Data extraction and quality assessment was completed by the same pair of reviewers that were previously referenced. Any discrepancies were handled in the same way that was previously mentioned.

Based on the methodology of Tannenbaum et $a l,{ }^{6}$ the included CPGs were first screened electronically for keywords: sex, gender, women, men, woman, man, boy, girl and pregnan*. A guideline was categorised as textpositive if it included any keywords in the main text. In this review, pregnancy was considered to be a subterm related to sex, recognising that it is a transient period of time in a female's life, rather than a sex-specific term.

Text-positive guidelines were grouped into four categories based on how sex and gender differences were incorporated into the guidelines. Category 1 was recommended evidence-based sex-related or gender-related diagnostic approach, ${ }^{6}$ Category 2 referred to a sex-related or gender-related management approach, ${ }^{6}$ Category 3 'made reference to sex or gender within epidemiological data, risk factors or prognostic data, but did not make suggestions for diagnosis or clinical management ${ }^{6},{ }^{6}$ and Category 4 'mentioned sex or gender keywords superficially'. ${ }^{6}$ In this review, the term superficial was used to describe the use of sex or gender terms without additional context or consideration as it relates to the literature or guideline recommendations. Further analysis considered the correct use of 'sex' and 'gender' terms, as defined by the Government of Canada. ${ }^{7}$ If the correct use could not be determined, guidelines were rated as 'unclear'. Lastly, investigators examined whether the authors considered sex and gender representation in the development of each guideline committee.

\section{Methodological quality assessment}

The Appraisal of Guidelines for Research and Evaluation II (AGREE II) ${ }^{16}$ tool was used to assess the quality of the CPGs. ${ }^{16}$ A calibration of the first three CPG's was completed prior to completing the quality assessment in pairs. A threshold of $60 \%$ was used to evaluate the overall quality for the final score of each domain of the AGREE II. ${ }^{16}{ }^{17}$ When $\geq 5$ domains had a score of greater than $60 \%$, the guideline was defined as high quality. ${ }^{17}$ When three or four of the domains had a score of greater than $60 \%$ and when less than or equal to two domains scored greater than $60 \%$, the guidelines were defined as average quality and low quality, respectively. ${ }^{17}$ The total score of each guideline and the domains were calculated. The median scores were used to examine any superficial relationships between the quality of the guideline and the likeliness of integrating sex or gender terms.

\section{RESULTS}

The electronic searches conducted from 2010 to March 2020 identified 14117 studies (see figure 1 for PRISMA flow diagram). We identified 235 CPGs, from which,
199 were excluded. Reasons for exclusion included: being published before 2010 ( $n=22)$, wrong study design $(n=80)$, not accessible in English $(n=34)$, wrong patient population $(n=5)$, not within the scope of physiotherapy $(n=10)$, outdated version of CPG $(n=6)$ or inaccessible $(n=42)$ (online supplemental appendix B). Thirty-six CPGs were included in the review. ${ }^{18-53}$

\section{Study characteristics}

Most of the guidelines were from the USA (31\%), ${ }^{2326-303839434548}$ Canada (11\%) $)^{19} 204952$ and North America (8\%). ${ }^{25} 3435$ The majority of CPGs (42\%) made recommendations in relation to a combination of NSLBP and specific LBP, ${ }^{18-20} 232429333739434748$ 50-52 or NSLBP (39\%) alone. $212225272830364244-464953$ Four CPGs (11\%) focussed on specific LBP, ${ }^{26} 323435$ two (5\%) focussed on LBP prevention ${ }^{40}{ }^{41}$ and one CPG $(3 \%)$ focussed on a combination of NSLBP, specific LBP and pathological LBP. $^{31}$

The majority of the guidelines $(53 \%)$ made reference to all durations of LBP. ${ }^{18} 19212224252729-31333839424349-5153$ Five CPGs $(14 \%)$ made recommendations based on a combination of acute, subacute or chronic LBP, ${ }^{20} 45474852$ four (11\%) referred strictly to chronic, ${ }^{26283744}$ two (5\%) were in relation to acute $\mathrm{LBP}^{2346}$ and the remaining six CPGs (17\%) did not specify duration..$^{34-36} 4041$ There were two CPGs that focussed on diagnosis, ${ }^{30} 39$ nine focussed on management ${ }^{192428324344475253}$ and four CPGs focussed on prevention..$^{21} 364041$ The majority of the CPGs provided information on both diagnosis and management of LBP. ${ }^{18} 20222325-27293133-35373842454648-51$

\section{Inclusion of sex/gender terms}

There were $\mathrm{n}=15(42 \%)$ text-positive CPGs for sex and gender terms 182023272930373841424446484953 and n=21 (58\%) text-negative CPGs ${ }^{19} 2122$ 24-26 28 31-36 3940434547 50-52 when pregnancy-related terms were included. Table 1 depicts the categories for text-positive guidelines, and the AGREE $\mathrm{II}^{16}$ score for each text-positive and text-negative guideline. Category 1 and/or Category 2 guidelines which related to diagnosis and management, respectively, made up 33\% of the text-positive guidelines. There were two CPGs that were identified as both Category 1 and Category $2,{ }^{23} 48$ and three guidelines that were identified as only Category $2 .^{4453}$ Nine CPGs were identified as Category $3(60 \%)^{20} 2729303738414246$ making reference to sex or gender terms in relation to epidemiology, prognosis or risk factors. There was only one Category 4 guideline, which superficially mentioned sex or gender terms ${ }^{49}$ without providing further context.

When pregnancy-related terms were excluded from the results, the lack of sex and gender integration was more pronounced (online supplemental appendix C). No guidelines made reference to sex or gender considerations in relation to LBP diagnosis, and only one guideline considered gender differences in management. ${ }^{23}$ Eight guidelines made reference to sex or gender terms in relation to epidemiology, prognosis or risk 

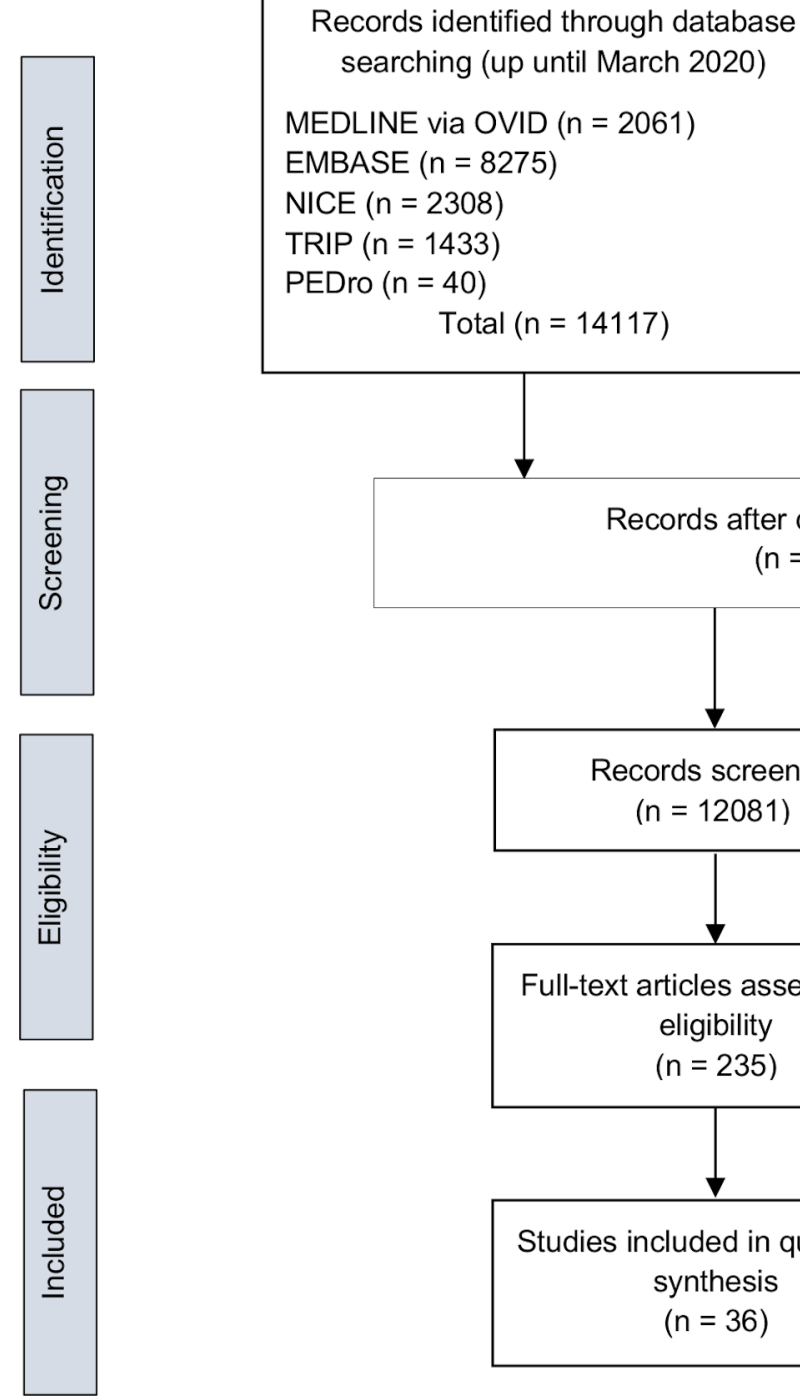

Additional records identified through other sources $(n=26)$

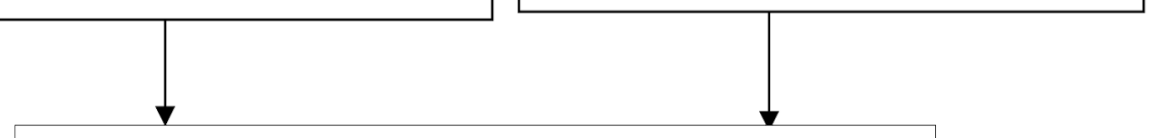

Records after duplicates removed $(n=12081)$

Figure 1 PRISMA flow diagram

factors. ${ }^{20} 27293037414246$ These results further depict the lack of sex or gender considerations beyond pregnancy.

\section{Sex/gender keywords}

Examples of paraphrased quotes retrieved from all of the text-positive CPGs were depicted in table 2. The quotes were organised by their respective categories (1 to 4), based off of the methodology by Tannenbaum et $a l^{6}{ }^{6}$ Within Category 1 there were two guidelines that provided recommendations for contraindications against imaging techniques for pregnancy. ${ }^{23} 48$ One of the guidelines gave an additional Category 1 recommendation with regards to clinical examination. ${ }^{48}$ For example, flexion and extension movements were contraindicated during clinical exams of patients who were pregnant. ${ }^{48}$ Within Category 2, there were five studies that gave specific management recommendations in regard to pregnancy considerations. ${ }^{18} 23444853$ Pregnancy-specific recommendations included rehabilitation strategies, contraindications to electrotherapy, precautions to acupuncture and precautions or contraindications for certain medications. ${ }^{1823444853}$ There was only one guideline within Category 2 that provided a management recommendation that was not specific to pregnancy. ${ }^{23}$ The recommendation made reference to avoiding trunk extension/flexion exercises in women at risk for osteoporosis. ${ }^{23}$ The majority of the Category 1 and Category 2 recommendations were for specific considerations in pregnancy.

Category 3 CPGs were most prevalent $(n=9)$ and integrated sex and gender terms most frequently. 2029303738414246 Category 3 CPGs integrated sex or gender terms into epidemiology, risk factors and care-seeking behaviours. ${ }^{20} 2729303738414246$ CPGs reported that women tend to have a higher prevalence of LBP and are more likely to seek care for $\mathrm{LBP}^{20} 273742$ One pregnancy-specific reference was made within Category 3 , stating that two-thirds of pregnant women experience LBP. $^{38}$ Category 3 was the only category that referenced male sex or gender, stating that men, more often than women, experience LBP as a result of manual material 
Table 1 Sex and gender text-positive clinical practice guidelines and text-negative clinical practice guidelines with the corresponding AGREE II score

\begin{tabular}{|c|c|c|c|c|}
\hline Author & Organisation and country & Title & $\mathbf{O A}^{*}$ & Quality† \\
\hline \multicolumn{5}{|l|}{ Category 1 and $2 \ddagger$} \\
\hline Chiodo et al $2010^{23}$ & $\begin{array}{l}\text { University of Michigan Health } \\
\text { System (USA) }\end{array}$ & $\begin{array}{l}\text { Acute low back pain: guidelines for clinical care (with } \\
\text { consumer summary) }\end{array}$ & 4.5 & Low \\
\hline Thorson et al $2018^{48}$ & $\begin{array}{l}\text { Institute for Clinical Systems } \\
\text { Improvement (USA) }\end{array}$ & Low back pain, adult acute and subacute & 5.5 & Average \\
\hline
\end{tabular}

\section{Category $2 \S$}

\begin{tabular}{|c|c|c|c|c|}
\hline Arvin et al $2016^{18}$ & $\begin{array}{l}\text { National Institute for Health } \\
\text { and Care Excellence (UK) }\end{array}$ & $\begin{array}{l}\text { Low back pain and sciatica in over } 16 \mathrm{~s} \text { : assessment } \\
\text { and management - NICE guideline }\end{array}$ & 5.5 & High \\
\hline Rached et al $2013^{44}$ & $\begin{array}{l}\text { Brazilian Association of } \\
\text { Physical Medicine and } \\
\text { Rehabilitation (Brazil) }\end{array}$ & Chronic non-specific low back pain: rehabilitation & 3.5 & Average \\
\hline Zhao et al $2016^{53}$ & $\begin{array}{l}\text { Institute of Acupuncture and } \\
\text { Moxibustion (China) }\end{array}$ & $\begin{array}{l}\text { Clinical practice guidelines of using acupuncture for } \\
\text { low back pain }\end{array}$ & 2.5 & Low \\
\hline
\end{tabular}

\section{Category 3ף}

\begin{tabular}{|c|c|c|c|c|}
\hline Bussières et al $2018^{20}$ & $\begin{array}{l}\text { Canadian Chiropractic } \\
\text { Guideline Initiative (Canada) }\end{array}$ & $\begin{array}{l}\text { Spinal manipulative therapy and other conservative } \\
\text { treatments for low back pain: a guideline from the } \\
\text { Canadian Chiropractic Guideline Initiative (with } \\
\text { consumer summary) }\end{array}$ & 6 & High \\
\hline Delitto et al $2012^{27}$ & $\begin{array}{l}\text { American Physical Therapy } \\
\text { Association (USA) }\end{array}$ & $\begin{array}{l}\text { Low back pain clinical practice guidelines linked } \\
\text { to the international classification of functioning, } \\
\text { disability and health from the orthopaedic section } \\
\text { of the American Physical Therapy Association (with } \\
\text { consumer summary) }\end{array}$ & 4.5 & Low \\
\hline Hegmann et al $2016^{29}$ & $\begin{array}{l}\text { American College of } \\
\text { Occupational and } \\
\text { Environmental Medicine (USA) }\end{array}$ & Low back disorders & 4.5 & Low \\
\hline Hegmann et al $2019^{30}$ & $\begin{array}{l}\text { American College of } \\
\text { Occupational and } \\
\text { Environmental Medicine (USA) }\end{array}$ & Diagnostic tests for low back disorders & 5 & Average \\
\hline Lee et al $2013^{37}$ & British Pain Society (UK) & $\begin{array}{l}\text { Low back and radicular pain: a pathway for care } \\
\text { developed by the British Pain Society. }\end{array}$ & 3.5 & Low \\
\hline Pangarkar et al $2019^{38}$ & $\begin{array}{l}\text { US Department of Veteran } \\
\text { Affairs / US Department of } \\
\text { Defence (USA) }\end{array}$ & $\begin{array}{l}\text { VA/DoD clinical practice guideline: diagnosis and } \\
\text { treatment of low back pain }\end{array}$ & 4 & Average \\
\hline Petit et al $2016^{41}$ & $\begin{array}{l}\text { French Society of } \\
\text { Occupational Medicine } \\
\text { (France) }\end{array}$ & $\begin{array}{l}\text { French good practice guidelines for management of } \\
\text { the risk of low back pain among workers exposed } \\
\text { to manual material handling: hierarchical strategy of } \\
\text { risk assessment of work situations }\end{array}$ & 2.5 & Low \\
\hline Picelli et al $2016^{42}$ & $\begin{array}{l}\text { The Italian Conference on } \\
\text { Pain in Neurorehabilitation } \\
\text { (Italy) }\end{array}$ & $\begin{array}{l}\text { Headache, low back pain, other nociceptive and } \\
\text { mixed pain conditions in neurorehabilitation. } \\
\text { Evidence and recommendations from the } \\
\text { Italian Consensus Conference on Pain in } \\
\text { Neurorehabilitation }\end{array}$ & 4 & Average \\
\hline Staal et al $2013^{46}$ & $\begin{array}{l}\text { Royal Dutch Society } \\
\text { for Physical Therapy } \\
\text { (Netherlands) }\end{array}$ & $\begin{array}{l}\text { KNGF clinical practice guideline for physical therapy } \\
\text { in patients with low back pain }\end{array}$ & 3 & Average \\
\hline
\end{tabular}

\section{Category $\mathbf{4}^{\text {**}}$}

\begin{tabular}{|c|c|c|c|c|}
\hline $\begin{array}{l}\text { LBP working group } \\
\text { toward optimised } \\
\text { practice } 2017\end{array}$ & $\begin{array}{l}\text { LBP working group toward } \\
\text { optimised practice (Canada) }\end{array}$ & $\begin{array}{l}\text { Evidence-informed primary care management of low } \\
\text { back pain }\end{array}$ & 3.5 & Low \\
\hline \multicolumn{5}{|c|}{ Text-negative guidelines†† } \\
\hline Brosseau et al $2012^{19}$ & $\begin{array}{l}\text { Ottawa Methods Group } \\
\text { (Canada) }\end{array}$ & $\begin{array}{l}\text { Ottawa panel evidence-based clinical practice } \\
\text { guidelines on therapeutic massage for low back pain }\end{array}$ & 4 & Low \\
\hline
\end{tabular}


Table 1 Continued

\begin{tabular}{|c|c|c|c|c|}
\hline Author & Organisation and country & Title & $\mathrm{OA}^{*}$ & Quality† \\
\hline Cheng et al $2012^{21}$ & $\begin{array}{l}\text { Guideline Development } \\
\text { Working Group (Hong Kong) }\end{array}$ & $\begin{array}{l}\text { Evidence-based guideline on prevention and } \\
\text { management of low back pain in working population }\end{array}$ & 4 & Low \\
\hline
\end{tabular}
in primary care

\begin{tabular}{|c|c|c|c|c|}
\hline Chenot et al $2017^{22}$ & $\begin{array}{l}\text { National Programme for } \\
\text { Disease Management } \\
\text { Guidelines (Germany) }\end{array}$ & $\begin{array}{l}\text { Clinical practice guideline: non-specific low back } \\
\text { pain }\end{array}$ & 3 & Low \\
\hline Chou et al $2018^{24}$ & $\begin{array}{l}\text { Global Spine Care Initiative } \\
\text { (Global) }\end{array}$ & $\begin{array}{l}\text { The Global Spine Care Initiative: applying evidence- } \\
\text { based guidelines on the non-invasive management } \\
\text { of back and neck pain to low-income and middle- }\end{array}$ & 4 & Low \\
\hline
\end{tabular}
income communities

\begin{tabular}{|c|c|c|c|c|}
\hline Chutkan et al $2020^{25}$ & $\begin{array}{l}\text { North American Spine Society } \\
\text { (North America) }\end{array}$ & $\begin{array}{l}\text { Evidence-based clinical guidelines for } \\
\text { multidisciplinary spine care: diagnosis and treatment } \\
\text { of low back pain }\end{array}$ & 5 & Average \\
\hline Deer et al $2019^{26}$ & $\begin{array}{l}\text { Lumbar Spinal Stenosis } \\
\text { Consensus Group (USA) }\end{array}$ & $\begin{array}{l}\text { The MIST guidelines: the lumbar spinal stenosis } \\
\text { consensus group guidelines for minimally invasive } \\
\text { spine treatment }\end{array}$ & 3 & Low \\
\hline Globe et al $2016^{28}$ & $\begin{array}{l}\text { Council on Chiropractic } \\
\text { Guidelines and Practice } \\
\text { Parameters (USA) }\end{array}$ & $\begin{array}{l}\text { Clinical practice guideline: chiropractic care for low } \\
\text { back pain }\end{array}$ & 5.5 & High \\
\hline Hussein et al $2016^{31}$ & $\begin{array}{l}\text { Malaysian Association for the } \\
\text { Study of Pain, Spine Society } \\
\text { Malaysia (Malaysia) }\end{array}$ & $\begin{array}{l}\text { The Malaysian low back pain management } \\
\text { guidelines }\end{array}$ & 2.5 & Low \\
\hline Jun et al $2017^{32}$ & $\begin{array}{l}\text { Korean Institute of Oriental } \\
\text { Medicine (Korea) }\end{array}$ & $\begin{array}{l}\text { Korean medicine clinical practice guideline for } \\
\text { lumbar herniated intervertebral disc in adults: an } \\
\text { evidence-based approach }\end{array}$ & 4 & Low \\
\hline Kreiner et al $2013^{35}$ & $\begin{array}{l}\text { North American Spine Society } \\
\text { (North America) }\end{array}$ & $\begin{array}{l}\text { An evidence-based clinical guideline for the } \\
\text { diagnosis and treatment of degenerative lumbar } \\
\text { spinal stenosis (update) }\end{array}$ & 4 & Low \\
\hline Kreiner et al $2014^{34}$ & $\begin{array}{l}\text { North American Spine Society } \\
\text { (North America) }\end{array}$ & $\begin{array}{l}\text { An evidence-based clinical guideline for the } \\
\text { diagnosis and treatment of lumbar disc herniation } \\
\text { with radiculopathy }\end{array}$ & 4 & Low \\
\hline Kuijer et al $2014^{36}$ & $\begin{array}{l}\text { Dutch Government } \\
\text { Occupational Health and } \\
\text { Safety (Netherlands) }\end{array}$ & $\begin{array}{l}\text { An evidence-based multidisciplinary practice } \\
\text { guideline to reduce the workload due to lifting for } \\
\text { preventing work-related low back pain }\end{array}$ & 4.5 & Average \\
\hline Sparks et al $2017^{45}$ & $\begin{array}{l}\text { Kaiser Foundation Health Plan } \\
\text { of Washington (USA) }\end{array}$ & Non-specific back pain guideline & 3.5 & Low \\
\hline $\begin{array}{l}\text { Stochkendahl et al } \\
2017^{47}\end{array}$ & $\begin{array}{l}\text { Danish Health Authority } \\
\text { (Denmark) }\end{array}$ & $\begin{array}{l}\text { National clinical guidelines for non-surgical treatment } \\
\text { of patients with recent onset low back pain or } \\
\text { lumbar radiculopathy }\end{array}$ & 4.5 & Average \\
\hline Valdecañas $2017^{50}$ & $\begin{array}{l}\text { Philippine Academy of } \\
\text { Rehabilitation Medicine } \\
\text { (Philippines) }\end{array}$ & $\begin{array}{l}\text { Clinical practice guidelines on the diagnosis and } \\
\text { management of low back pain }\end{array}$ & 4 & Low \\
\hline
\end{tabular}




\begin{tabular}{|c|c|c|c|c|}
\hline Author & Organisation and country & Title & $\mathbf{O A}^{*}$ & Quality \\
\hline $\begin{array}{l}\text { Van Wambeke et al } \\
2017^{51}\end{array}$ & $\begin{array}{l}\text { Belgian Healthcare } \\
\text { Knowledge Centre (Belgium) }\end{array}$ & $\begin{array}{l}\text { Low back pain and radicular pain: assessment and } \\
\text { management }\end{array}$ & 6 & High \\
\hline Wong et al $2017^{52}$ & $\begin{array}{l}\text { Ontario Protocol for Traffic } \\
\text { Injury Management (OPTIMa) } \\
\text { Collaboration (Canada) }\end{array}$ & $\begin{array}{l}\text { Clinical practice guidelines for the non-invasive } \\
\text { management of low back pain: a systematic review } \\
\text { by the Ontario Protocol for Traffic Injury Management } \\
\text { Collaboration }\end{array}$ & 3.5 & Low \\
\hline
\end{tabular}

${ }^{*}$ Overall assessment score.

†High quality was defined when 5 or more domains scored $>60 \%$, average quality when 3 or 4 domains scored $>60 \%$ and low quality when $\leq 2$ domains scored $>60 \%$.

$\ddagger$ Recommended evidence-based sex-related or gender-related diagnostic or management approach.

$\S$ Recommended evidence-based sex-related or gender-related management approach.

१Made reference to sex or gender within epidemiological data, risk factors or prognostic data, but did not make suggestions for diagnosis or clinical management.

${ }^{\star \star}$ Mentioned sex or gender keywords superficially.

††Did not mention sex or gender terms in text.

AGREE II, Appraisal of Guidelines for Research and Evaluation II; DoD, Department of Defence; LBP, low back pain; VA, Veteran Affairs.

handling. ${ }^{41}$ Men also have a higher risk of developing ankylosing spondylitis and spondylolysis. ${ }^{29} 3046$ The only CPG that was considered Category 4, referenced pregnancy within the exclusion criteria. ${ }^{49}$

\section{Appropriateness of sex/gender use}

None of the identified text-positive CPGs provided a definition of sex or gender within the guideline, ${ }^{1820232730373841424446484953}$ and only three CPGs ${ }^{304246}$ had appropriate use of the terms according to the Government of Canada. ${ }^{7}$ Two CPGs did not contain enough information to determine if the terms were used properly. ${ }^{271}$ The remaining 10 CPGs had inappropriate use of sex and gender terms, for example, using gender terms when relating to biological attributes. 18202329373844484953 Only one CPG considered sex and gender representation in the formation of the guideline committee. ${ }^{39}$

\section{Methodological quality assessment}

The total score for each domain of the AGREE $\mathrm{II}^{16}$ as well as the final overall quality was determined for each guideline (online supplemental appendix D). Of the 36 evaluated guidelines, $4^{18} 192851$ were high quality $(11 \%)$, $12^{25} 303336383942-4446-48$ were average quality (33\%) and $20^{19} 21-24262729313234353740414549505253$ were low quality $(56 \%)$. Only two guidelines ${ }^{20} 51$ reached an acceptable $(\geq 60 \%)$ score in all six AGREE $\mathrm{II}^{16}$ domains. The remaining CPGs had at least one domain with a low score $(<60 \%)$. Of all domains, Domain 4 ('Clarity of Presentation') had the highest mean quality score $79 \%$ and Domain 5 ('Applicability') had the lowest mean quality score $22 \%$. The overall median AGREE $\mathrm{II}^{16}$ score of all CPGs, as well as text-positive CPGs, was 4 with an IQR of 1 . There was no observable relationship between the quality of the guideline and likeliness of integrating sex or gender terms. There were five guidelines ${ }^{22} 29303747$ for which the referenced methodology or appendices were not in English, thus the scores may not be a true representation of their methodological quality. ${ }^{16}$

\section{DISCUSSION Major findings}

Overall, the CPGs identified in this scoping review had poor integration of sex and gender considerations, and the majority of CPGs did not mention sex or gender terms. When sex or gender terms were mentioned, they were primarily in relation to epidemiology, risk factors or prognostic data. There were few CPGs that integrated any sex or gender differences into their recommendations regarding diagnosis or treatment of LBP. The majority of the time, recommendations were for specific considerations in pregnancy. ${ }^{18} 23444853$ The majority of guidelines used inappropriate terms when referring to either sex or gender. Often, sex and gender terms were used interchangeably, and there was very limited separation between the use of the biological sex terms and social gender terms. Only one guideline committee acknowledged if diversity of sex and gender was considered in the development of the committee. ${ }^{39}$ No CPG provided a definition of sex or gender within the guideline.

The findings of this review had both consistencies and inconsistencies to a similar study conducted by Tannenbaum et $a l^{6}$ Tannenbaum et at found that $67 \%$ of the included CPGs were text-positive for sex or gender terms. Thirty-five per cent of text-positive CPGs fell under Category 1 and Category 2 recommendations (reported screening, diagnosis or management considerations specific to sex or gender), and the majority of CPGs $(41 \%)$ made reference to sex or gender considerations in epidemiological or risk factors. It is clear that this scoping review had a much lower text-positive response than Tannenbaum et $a l^{6}{ }^{6}$ with only $42 \%$ of CPGs being textpositive. The inconstancies found between the number of text-positive guidelines may be due to differences in study methodology. Tannenbaum et at only included Canadian studies, whereas this review was expanded to international guidelines. Research funders in Canada, such as the Canadian Institute of Health Research (CIHR), are a 
Table 2 Summary of the use of sex and gender terms in relation to the respective category

\begin{tabular}{|c|c|}
\hline Author / national body & Paraphrased quote from guideline \\
\hline \multicolumn{2}{|c|}{ Category 1: Recommends evidence-based sex-related or gender-related diagnostic approach } \\
\hline Chiodo et al $2010^{23}$ & IMAGING: X-rays, CT scans and bone scans are contraindicated during pregnancy. \\
\hline $\begin{array}{l}\text { University of Michigan Health System } \\
\text { (USA) }\end{array}$ & $\begin{array}{l}\text { Consultation with a radiologist is strongly advised when considering MRI scanning } \\
\text { during pregnancy. }\end{array}$ \\
\hline
\end{tabular}

Thorson et al $2018^{48} \quad$ CLINICAL EXAM: The physical examination is similar to non-pregnant patients with low back pain, although lumbar flexion will be limited as the pregnancy progresses.

Institute for Clinical Systems IMAGING: Lumbar radiographs are routinely avoided during pregnancy due to concern Improvement (USA) for fetal health. MRI is the test of choice for severe pregnancy-related low back pain.

Category 2: Recommends evidence-based sex-related or gender-related management approach

Arvin et al 2016 ${ }^{18} \quad$ RADIOFREQUENCY DENERVATION: The Guideline Development Group (GDG) agreed that this recommendation (indications for referral for appropriateness of radiofrequency denervation) would equally apply for pregnant women and this should be considered on a case by case basis.

$\begin{array}{ll}\text { National Institute for Health and Care } & \text { MEDICATION: The Guideline Development Group (GDG) agreed that British } \\ \text { Excellence (UK) } & \text { National Formulary (BNF) guidance should be followed for all pharmacological } \\ & \text { recommendations, including considerations for pregnant women, and therefore did not } \\ & \text { consider that separate recommendations were required for pregnant women. }\end{array}$

Chiodo et al $2010^{23}$

REHABILITATION: In older women or persons at risk for osteoporosis, trunk extension exercises are preventive, while trunk flexion exercises may increase the risk of osteoporotic fractures. Pregnant women with back pain may want to discuss with their obstetrical care provider different positions, strategies and methods of pain relief. This may include anaesthesia consultation (for labour and delivery) or referral to hospital or community based prophylactic back classes specifically designed for pregnancy.

University of Michigan Health System MEDICATION: Medications are limited and should be appropriate for a pregnant (USA) woman.

Rached et al $2013^{44} \quad$ ULTRASOUND: Therapeutic ultrasound is contraindicated in areas, such as in the eyeball, pregnant uterus, plastic endoprosthesis components, methacrylate and the heart.

Brazilian Association of Physical ELECTROTHERAPY: Percutaneous electrical nerve stimulation (acupuncture and Medicine and Rehabilitation (Brazil) electrical stimulation) is contraindicated in pacemaker users, individuals with epilepsy, heart problems, cognitive impairments and during the first 3 months of pregnancy, especially in the lumbar and abdominal areas.

Thorson et al $2018^{48}$ EPIDURAL STERIOD INJECTIONS: Pregnancy is a contraindication due to the use of Institute for Clinical Systems fluoroscopy.

Improvement (USA)

Zhao et al $2016^{53}$

Institute of Acupuncture and

Moxibustion (China)

COMPLEMENTARY MED: Acupotomy is applied very cautiously for women during menstruation or pregnancy. Moxibustion should be applied very cautiously for pregnant patients or patients with sensory impairment.

\section{Category 3: Referred to sex or gender within epidemiology data, risk factors or prognostic data, but did not make} recommendations

\begin{tabular}{ll}
$\begin{array}{l}\text { Bussières et al } 2018^{20} \\
\begin{array}{l}\text { Canadian Chiropractic Guideline } \\
\text { Initiative (Canada) }\end{array}\end{array}$ & $\begin{array}{l}\text { CARE SEEKING BEHAVIOURS: Most people with low-back pain consult a health } \\
\text { provider for this issue. It is more common for women to seek care along with individuals } \\
\text { with previous low back pain, poor general health and more disabling or more painful } \\
\text { episodes. }\end{array}$ \\
$\begin{array}{ll}\text { Delitto et al } 2012^{27} & \text { EPIDEMIOLOGY: Low back pain (LBP) prevalence appears to vary based on factors like } \\
\text { sex, age, education and occupation; with women having a higher prevalence than men. }\end{array}$ \\
$\begin{array}{l}\text { American Physical Therapy } \\
\text { Association (USA) }\end{array}$ \\
$\begin{array}{l}\text { gender, age, body build, strength and flexibility. Women may have almost three times } \\
\text { the risk of back pain as men. }\end{array}$ \\
$\begin{array}{l}\text { RISK FACTORS: The factors that predict unresponsiveness to epidural } \\
\text { glucocorticosteroid injections include potential sex differences. Male gender is at higher } \\
\text { risk for ankylosing spondylitis. }\end{array}$ \\
\hline
\end{tabular}


Table 2 Continued

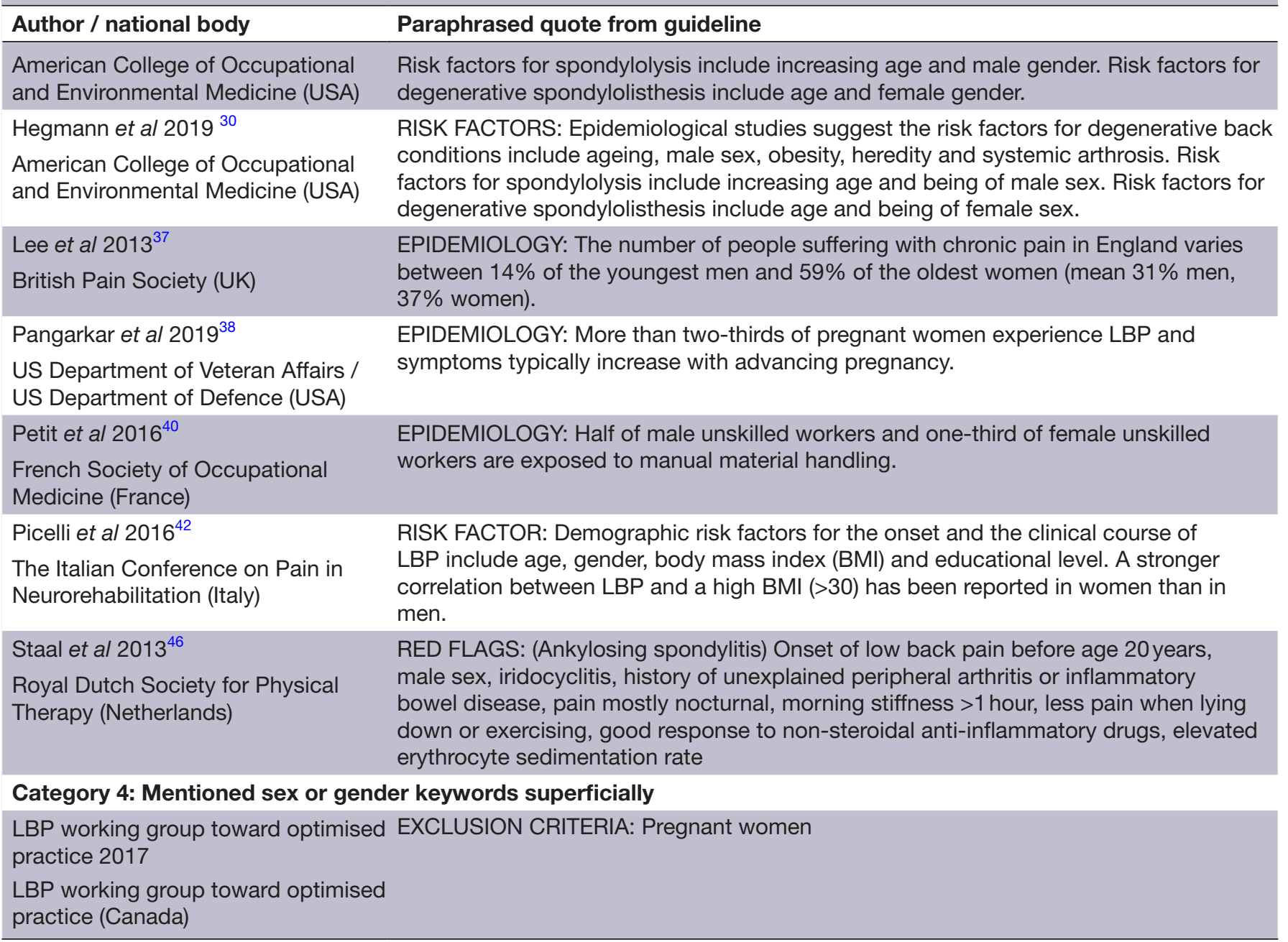

driving force behind sex and gender integration in Canadian research. ${ }^{54}$ Canadian guidelines may be more likely to integrate sex and gender considerations into research, compared with other countries, as a result of the CIHR.

Tannenbaum et at excluded studies that had key words specific to pregnancy, whereas this review included pregnancy as a sex term in order to be more inclusive. The majority of Category 1 and Category 2 recommendations in this review were related to pregnancy. When pregnancy terms were omitted, there were no guidelines that made reference to diagnosis, and only one guideline that referred to management. Sex and gender considerations need to go beyond pregnancy, teratogenicity or breastfeeding, and consider more complex interactions such as specific and non-specific LBP. Future studies should integrate sex and gender terms in relation to all age milestones, rather than solely focussing on transient periods, such us pregnancy. This approach to sex and gender integration would make recommendations applicable to a broader population.

\section{Strengths and limitations}

This scoping review used rigorous methodology to ensure low risk of bias and quality of reporting. The methodological framework for scoping reviews by Arksey and O'Malley, ${ }^{10}$ and Levac et $a l^{11}$ was used. The PRISMA guidelines for reporting were also followed. ${ }^{12}$ The study protocol was registered with OSF prior to title and abstract screening to ensure transparency of the process and reduce potential bias. ${ }^{13}$ A comprehensive search strategy was used, which was developed in partnership with a librarian. In addition, the AGREE II $^{16}$ was used to evaluate the quality of the included CPGs. ${ }^{16}$

Restricting the language to English only was a limitation of this review. This review only considered CPGs and excluded primary literature. It is possible that our results do not represent the current state of sex-based and genderbased primary research pertaining to LBP. Another limitation was limiting the inclusion criteria to the past 10 years. Earlier CPGs that integrated sex and gender terms may have been excluded by this narrow timeline. A 10-year cut-off was chosen because government bodies and experts began recognising the importance of sex and gender considerations in the literature after $2009 .{ }^{854} \mathrm{We}$ recognised that these changes would take a year or more to integrate into research, therefore, before 2010, it was unlikely that CPGs integrated sex or gender terms. 


\section{CONCLUSION}

This review provided insight on the current use of sex and gender terms in CPGs related to LBP. Integration of sex and gender considerations has the potential to guide future clinical practice and research, specifically regarding differences in the diagnosis, prognosis and management of LBP. This review is intended to be eyeopening for LBP researchers regarding the fact that sex and gender are not being integrated in current CPGs. The use of guides, such as the SAGER guidelines, should become a priority in the future. ${ }^{8}$ This review highlights that there are known sex and gender differences in management, epidemiology, risk factors and care-seeking behaviours in LBP, which should be considered during physiotherapy practice. Future research should consider examining both the inclusion and appropriateness of the use of a larger spectrum of gender specific terms (ie, non-binary), as current knowledge on this area of gender integration and research regarding LBP is limited. Clinicians should educate themselves on the differences between sex/gender and be cautious when using LBP recommendations from current CPGs.

Correction notice This article has been corrected since it first published. The provenance and peer review statement has been included.

Twitter Luciana G Macedo @gazzimacedo

Contributors All authors contributed to the study conception and design. Study design, data collection and analysis were performed by all authors. All authors read and approved the final manuscript.

Funding The authors have not declared a specific grant for this research from any funding agency in the public, commercial or not-for-profit sectors.

\section{Competing interests None declared.}

Patient consent for publication Not required.

Provenance and peer review Not commissioned; externally peer reviewed.

Open access This is an open access article distributed in accordance with the Creative Commons Attribution Non Commercial (CC BY-NC 4.0) license, which permits others to distribute, remix, adapt, build upon this work non-commercially, and license their derivative works on different terms, provided the original work is properly cited, appropriate credit is given, any changes made indicated, and the use is non-commercial. See: http://creativecommons.org/licenses/by-nc/4.0/.

\section{ORCID iDs}

Tori Rathbone http://orcid.org/0000-0003-1712-8548

Luciana G Macedo http://orcid.org/0000-0002-1840-2951

\section{REFERENCES}

1 Dionne CE, Dunn KM, Croft PR, et al. A consensus approach toward the standardization of back pain definitions for use in prevalence studies. Spine 2008;33:95-103.

2 Burton AK, Balagué F, Cardon G, et al. Chapter 2. European guidelines for prevention in low back pain : November 2004. Eur Spine J 2006;15 Suppl 2:s136-68.

3 Hartvigsen J, Hancock MJ, Kongsted A, et al. What low back pain is and why we need to pay attention. Lancet 2018;391:2356-67.

4 James SL, Abate D, Abate KH, et al. Global, regional, and national incidence, prevalence, and years lived with disability for 354 diseases and injuries for 195 countries and territories, 1990-2017: a systematic analysis for the global burden of disease study 2017. Lancet 2018;392:1789-858.

5 Fehrmann E, Kotulla S, Fischer L, et al. The impact of age and gender on the ICF-based assessment of chronic low back pain. Disabil Rehabil 2019;41:1190-9.
6 Tannenbaum C, Clow B, Haworth-Brockman M, et al. Sex and gender considerations in Canadian clinical practice guidelines: a systematic review. CMAJ Open 2017;5:E66-73.

7 Government of Canada. Health Portfolio sex and gender-based analysis policy. in: Gov. can, 2017. Available: https://www. canada.ca/en/health-canada/corporate/transparency/corporatemanagement-reporting/heath-portfolio-sex-gender-based-analysispolicy.html

8 Heidari S, Babor TF, De Castro P, et al. Sex and gender equity in research: rationale for the SAGER guidelines and recommended use. Res Integr Peer Rev 2016;1:2.

9 Daudt HML, van Mossel C, Scott SJ. Enhancing the scoping study methodology: a large, inter-professional team's experience with Arksey and O'Malley's framework. BMC Med Res Methodol 2013;13:48

10 Arksey H, O'Malley L. Scoping studies: towards a methodological framework. Int J Soc Res Methodol 2005;8:19-32.

11 Levac D, Colquhoun H, O'Brien KK. Scoping studies: advancing the methodology. Implement Sci 2010;5:69.

12 Tricco AC, Lillie E, Zarin W, et al. PRISMA extension for scoping reviews (PRISMA-ScR): checklist and explanation. Ann Intern Med 2018;169:467.

13 Rathbone T, Cimek T, Riazi S. Protocol for sex and gender considerations in low back pain clinical practice guidelines: a scoping review 2020 https://doi.org/10.17605/OSF.IO/7S9BD

14 Oliveira CB, Maher CG, Pinto RZ, et al. Clinical practice guidelines for the management of non-specific low back pain in primary care: an updated overview. Eur Spine J 2018;27:2791-803.

15 Veritas Health Innovation. Covidence systematic review software. Melbourne, Australia.

16 Brouwers MC, Kho ME, Browman GP, et al. Agree II: advancing Guideline development, reporting and evaluation in health care. Can Med Assoc J 2010;182:E839-42.

17 Doniselli FM, Zanardo M, Manfrè L, et al. A critical appraisal of the quality of low back pain practice guidelines using the agree II tool and comparison with previous evaluations: a EuroAIM initiative. Eur Spine J 2018;27:2781-90.

18 Arvin B, Bernstein I, Blowey S. Low back pain and sciatica in over 16s: assessment and management - NICE quideline, 2016.

19 Brosseau L, Wells GA, Poitras S, et al. Ottawa panel evidence-based clinical practice guidelines on therapeutic massage for low back pain. J Bodyw Mov Ther 2012;16:424-55

20 Bussières AE, Stewart G, Al-Zoubi F, et al. Spinal manipulative therapy and other conservative treatments for low back pain: a guideline from the Canadian chiropractic guideline initiative. $J$ Manipulative Physiol Ther 2018;41:265-93.

21 Cheng L, KKS L, Lam WK. Evidence-Based guideline on prevention and management of low back pain in working population in primary care. Xianggang Uankeyixueyuan Yuekan Hong Kong Pract 2012;34:106-15.

22 Chenot J, Greitemann B, Kladny B. Non-Specific low back pain. Dtsch Arzteblatt Int 2017;114:883-90.

23 Chiodo AE, Alvarez DJ, Graziano GP. Acute low back pain: guidelines for clinical care [with consumer summary], 2010.

24 Chou R, Côté P, Randhawa K, et al. The global spine care initiative: applying evidence-based guidelines on the non-invasive management of back and neck pain to low- and middle-income communities. Eur Spine J 2018;27:851-60.

25 Chutkan NB, Lipson AC, Lisi AJ. Evidence-Based clinical guidelines for multidisciplinary spine care: diagnosis and treatment of low back pain 2020.

26 Deer TR, Grider JS, Pope JE, et al. The mist guidelines: the lumbar spinal stenosis consensus group guidelines for minimally invasive spine treatment. Pain Pract 2019;19:250-74.

27 Delitto A, George SZ, Dillen LV. Low back pain clinical practice guidelines linked to the International Classification of Functioning, Disability, and Health from the Orthopaedic Section of the American Physical Therapy Association [with consumer summary]. J Orthop Sports Phys Ther 2012;42:A1-57.

28 Globe G, Farabaugh RJ, Hawk C, et al. Clinical practice guideline: chiropractic care for low back pain. J Manipulative Physiol Ther 2016;39:1-22.

29 Hegmann KT, Travis R, Belcourt R. Low back disorders, 2016.

30 Hegmann KT, Travis R, Belcourt RM, et al. Diagnostic tests for low back disorders. J Occup Environ Med 2019;61:e155-68.

31 Hussein AMM, Singh D, Mansor M. The Malaysian low back pain management guidelines, 2016.

32 Jun JH, Cha Y, Lee JA, et al. Korean medicine clinical practice guideline for lumbar herniated intervertebral disc in adults: an evidence based approach. Eur J Integr Med 2017;9:18-26. 
33 Kassolik K, Rajkowska-Labon E, Tomasik T, et al. Recommendations of the Polish Society of physiotherapy, the Polish Society of family medicine and the College of family physicians in Poland in the field of physiotherapy of back pain syndromes in primary health care. Fmpcr 2017;3:323-34.

34 Kreiner DS, Hwang SW, Easa JE, et al. An evidence-based clinical guideline for the diagnosis and treatment of lumbar disc herniation with radiculopathy. Spine $J$ 2014;14:180-91.

35 Kreiner DS, Shaffer WO, Baisden JL, et al. An evidence-based clinical guideline for the diagnosis and treatment of degenerative lumbar spinal stenosis (update). Spine J 2013;13:734-43.

36 Kuijer PPF, Verbeek JH, Visser B, et al. An evidence-based multidisciplinary practice guideline to reduce the workload due to lifting for preventing work-related low back pain. Ann Occup Environ Med 2014;26:16.

37 Lee J, Gupta S, Price C, et al. Low back and radicular pain: a pathway for care developed by the British pain Society. $\mathrm{Br} J$ Anaesth 2013;111:112-20.

38 Pangarkar SS, Kang DG, Sandbrink F, et al. VA/DoD clinical practice guideline: diagnosis and treatment of low back pain. J Gen Intern Med 2019;34:2620-9.

39 Patel ND, Broderick DF, Burns J, et al. ACR Appropriateness Criteria Low Back Pain. J Am Coll Radiol 2016;13:1069-78.

40 Petit A, Rousseau S, Huez JF, et al. Pre-Employment examination for low back risk in workers exposed to manual handling of loads: French guidelines. Int Arch Occup Environ Health 2016;89:1-6.

41 Petit A, Mairiaux P, Desarmenien A, et al. French good practice guidelines for management of the risk of low back pain among workers exposed to manual material handling: hierarchical strategy of risk assessment of work situations. Work 2016;53:845-50.

42 Picelli A, Buzzi MG, Cisari C, et al. Headache, low back pain, other nociceptive and mixed pain conditions in neurorehabilitation. Evidence and recommendations from the Italian consensus conference on pain in neurorehabilitation. Eur J Phys Rehabil Med 2016;52:867-80.

43 Qaseem A, Wilt TJ, McLean RM, et al. Noninvasive treatments for acute, subacute, and chronic low back pain: a clinical practice guideline from the American College of physicians. Ann Intern Med 2017;166:514-30.

44 Rached R, da RCDP, Alfieri FM. Lombalgia inespecífica crônica: reabilitação. Rev Assoc Médica Bras 2013;59:536-53.

45 Sparks A, Cohen A, Adjao S. Back pain. Kais perm clin Guidel, 2017.

46 Staal J, Hendriks E, Heijmans M. KNGF clinical practice guideline for physical therapy in patients with low back pain, 2013.

47 Stochkendahl MJ, Kjaer P, Hartvigsen J, et al. National clinical guidelines for non-surgical treatment of patients with recent onset low back pain or lumbar radiculopathy. Eur Spine $J$ 2018;27:60-75.

48 Thorson D, Campbell R, Massey M. Low back pain, adult acute and subacute. insT clin Syst Improv, 2018.

49 Toward Optimized Practice (TOP) Low Back Pain Working Group. Evidence-Informed primary care management of low back pain: clinical practice guideline. toward optimized practice, 2017.

50 Valdecañas C, Ephraim D. Clinical practice guidelines on the diagnosis and management of low back pain, 2017.

51 Van Wambeke P, Desomer A, Ailliet L. Clinical guideline on low back pain and radicular pain. Tijdschr Voor Geneeskd 2017;73:1182-95.

52 Wong JJ, Côté P, Sutton DA, et al. Clinical practice guidelines for the noninvasive management of low back pain: a systematic review by the Ontario protocol for traffic injury management (optima) collaboration. Eur J Pain 2017;21:201-16.

53 Zhao H, LIU B-yan, LIU Z-shun, et al. Clinical practice guidelines of using acupuncture for low back pain. World $J$ Acupunct Moxibustion 2016;26:1-13.

54 Government of Canada Cl of HR. Sex, gender and health research in: can. insT. health Res 2019. [Epub ahead of print: 4 Jul 2020] https://cihr-irsc.gc.ca/e/50833.html 